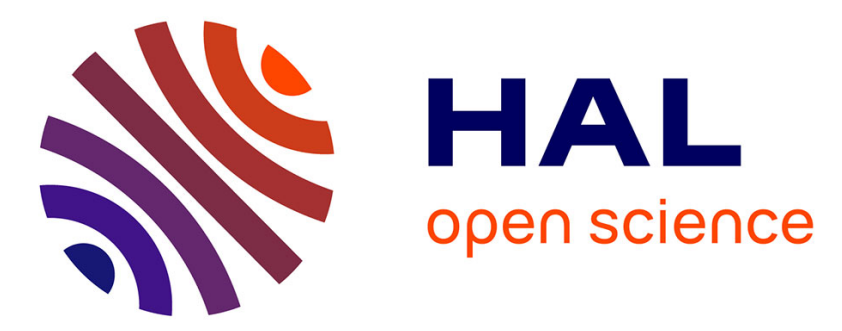

\title{
Nutritional state of the pollen beetle parasitoid Tersilochus heterocerus foraging in the field
}

Adrien Rusch, Séverine Suchail, Muriel Valantin-Morison, Jean-Pierre

Sarthou, Jean Roger-Estrade

\section{- To cite this version:}

Adrien Rusch, Séverine Suchail, Muriel Valantin-Morison, Jean-Pierre Sarthou, Jean Roger-Estrade. Nutritional state of the pollen beetle parasitoid Tersilochus heterocerus foraging in the field. BioControl, 2013, 58 (1), pp.17-26. 10.1007/s10526-012-9463-1 . hal-02047766

HAL Id: hal-02047766

https://hal-univ-avignon.archives-ouvertes.fr/hal-02047766

Submitted on 7 Mar 2019

HAL is a multi-disciplinary open access archive for the deposit and dissemination of scientific research documents, whether they are published or not. The documents may come from teaching and research institutions in France or abroad, or from public or private research centers.
L'archive ouverte pluridisciplinaire HAL, est destinée au dépôt et à la diffusion de documents scientifiques de niveau recherche, publiés ou non, émanant des établissements d'enseignement et de recherche français ou étrangers, des laboratoires publics ou privés. 
Nutritional state of the pollen beetle parasitoid Tersilochus heterocerus foraging in the field

\section{Adrien Rusch, Séverine Suchail, Muriel Valantin-Morison, Jean-Pierre Sarthou \& Jean Roger-Estrade}

\section{BioControl}

Journal of the International

Organization for Biological Control

ISSN 1386-6141

BioControl

DOI 10.1007/s10526-012-9463-1

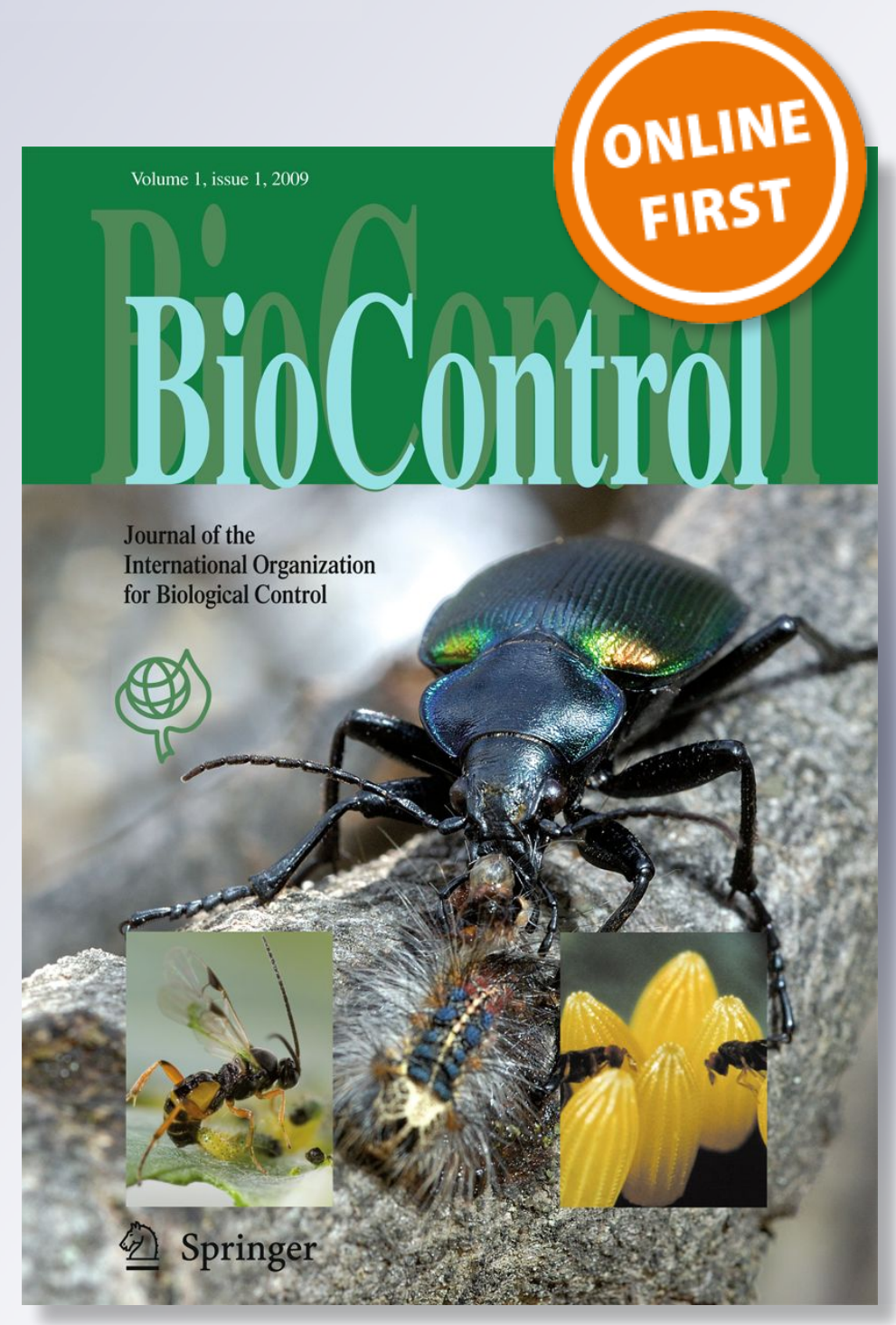

照 Springer 
Your article is protected by copyright and all rights are held exclusively by International Organization for Biological Control (IOBC). This e-offprint is for personal use only and shall not be self-archived in electronic repositories. If you wish to self-archive your work, please use the accepted author's version for posting to your own website or your institution's repository. You may further deposit the accepted author's version on a funder's repository at a funder's request, provided it is not made publicly available until 12 months after publication. 


\title{
Nutritional state of the pollen beetle parasitoid Tersilochus heterocerus foraging in the field
}

\author{
Adrien Rusch · Séverine Suchail • \\ Muriel Valantin-Morison · Jean-Pierre Sarthou • \\ Jean Roger-Estrade
}

Received: 3 January 2012 / Accepted: 24 May 2012

(C) International Organization for Biological Control (IOBC) 2012

\begin{abstract}
Many laboratory studies have demonstrated that parasitoids of various species depend on sugar sources such as nectar or honeydew. However, studies about nectar acquisition by parasitoids foraging in the field are scarce. Tersilochus heterocerus Thomson is one of the more abundant and widespread parasitoids of the pollen beetle (Meligethes aeneus $\mathrm{F}$.) but nothing is known about the nutritional ecology of this species. In this study we examined the nutritional
\end{abstract}

Handling Editor: Stefano Colazza

A. Rusch $(\square)$

Department of Ecology, Swedish University of Agricultural Sciences, Box 7044, 75007 Uppsala, Sweden e-mail: adrien.rusch@slu.se

A. Rusch

UMR INRA-ENITAB 1065 Santé et Agroécologie du Vignoble, Centre de recherches INRA de BordeauxAquitaine, Institut des Science de la Vigne et du Vin, BP 81, 33883 Villenave d'Ornon, France

\section{A. Rusch}

Université de Bordeaux, UMR1065, Bordeaux Sciences Agro, BP 81, 33883 Villenave d'Ornon cedex, France

\section{S. Suchail}

Biomarqueurs et Bioindicateurs Environnementaux, Institut Méditerranéen de Biodiversité et d'Ecologie marine et continentale, IMBE, UMR 7263, Universite d'Avignon et des Pays du Vaucluse Pole Agrosciences 301 rue Baruch de Spinoza, BP 21239, 84916 Avignon cedex 9, France

e-mail: Severine.Suchail@avignon.inra.fr state of T. heterocerus at the time of emergence and at various time periods throughout the season while foraging in the field using high-performance anionexchange chromatography. We found that: (i) $T$. heterocerus emerge with relatively small amounts of sugar, composed mainly of trehalose, glucose and fructose; (ii) the first parasitoids caught just after they appeared in the field at the beginning of oilseed rape flowering had already consumed significant amounts of sugar reserves; and (iii) the total amount of sugar at the end of flowering was always significantly higher

M. Valantin-Morison · J. Roger-Estrade

AgroParisTech, UMR 211 Agronomie, INRA/

AgroParisTech, BP 01, 78850 Thiverval-Grignon, France

e-mail: muriel.morison@grignon.inra.fr

J. Roger-Estrade

e-mail: estrade@grignon.inra.fr

J.-P. Sarthou

Toulouse University; ENSAT; UMR 1248 AGIR, 31326

Castanet Tolosan, France

e-mail: sarthou@ensat.fr

J.-P. Sarthou

INRA; UMR 1248 AGIR, 31326 Castanet Tolosan,

France 
than the total amount of sugar at the beginning of flowering. This study provides valuable insights into the acquisition of sugar in the field by the parasitoid $T$. heterocerus and suggests that nectar acquisition takes place in the oilseed rape field or in the surrounding landscape.

Keywords Oilseed rape - Tersilochus heterocerus . Parasitoid · Nectar · Carbohydrate · HPAEC . Conservation biological control

\section{Introduction}

Parasitoid wasps are important biological control agents in agroecosystems (Hawkins et al. 1997). Various studies have reported that floral resources can provide key energetic elements to parasitoids which can lead to enhanced pest biocontrol (Berndt et al. 2002; Tylianakis et al. 2004). It has been demonstrated that some parasitoids are particularly dependent on carbohydrates as energy sources and that the availability of suitable sugar sources can play a major role in adult parasitoid longevity, fecundity, searching behavior and population dynamics (Lavandero et al. 2005; Winkler et al. 2006; Lee and Heimpel 2008). The major carbohydrate sources for adult parasitoids are believed to be sugarrich materials derived, directly or indirectly, from plants, such as nectar and honeydew (Jervis et al. 1993; Wäckers and van Rijn 2005). For host-feeding parasitoids, host haemolymph can also provide sugar but is generally considered a poor source because levels of carbohydrates are generally very low (Steppuhn and Wäckers 2004).

Sugar feeding enables parasitoids to maintain a high level of glycogen and slows down the rate of lipid decline which enhance egg production, female fecundity, longevity and foraging ability (Lee and Heimpel 2008). It has been shown that carbohydrate levels increase with sugar consumption and are thus considered a good indicator of the parasitoid's nutritional state in the field (Casas et al. 2003; Steppuhn and Wäckers 2004).

Complex landscapes with a high proportion of semi-natural habitats have been found to support higher natural pest control by parasitoids than simple landscapes with small amounts of semi-natural habitats (Bianchi et al. 2006). This positive effect of landscape complexity on biological control is assumed to be due to the provision of key resources for natural enemies such as food, overwintering sites or alternative hosts (Landis et al. 2000). A thorough understanding of the biology and patterns of resource utilization by parasitoids is necessary to interpret parasitism and population dynamics at the landscape level (Costamagna et al. 2004). Such knowledge is, however, usually lacking for numerous parasitoid species. In this paper, we focus on food resource acquisition by Tersilochus heterocerus Thomson (Hymenoptera: Ichneumonidae) foraging in the field.

Tersilochus heterocerus is one of the three most abundant and widespread parasitoids of the pollen beetle [Meligethes aeneus F., (Coleoptera: Nitidulidae)], a major oilseed rape (Brassica napus L.) pest, and can cause a high level of mortality in the pest population (Ulber et al. 2010). It is a univoltine, koinobiont, larval endoparasitoid of pollen beetle larvae (Jourdheuil 1960). Adults appear in the oilseed rape crop at the beginning of flowering (i.e. end of April, beginning of May in Western Europe) and females lay their eggs into host larvae located in buds or open flowers. Then, pollen beetle larvae drop to the ground and the parasitoid completes its larval development in a few days, killing its host and pupating in the top centimetres of the soil. Tersilochus heterocerus overwinters as diapausing adults in a cocoon and adults emerge the following spring from the soil of the previous-year oilseed rape fields (Ulber et al. 2010). According to Jourdheuil (1960), this species does not feed during imaginal activity and sexual maturation occurs during diapause and depends solely on lipid reserves accumulated during larval development within the host body. Females emerge with a high quantity of already mature eggs and can therefore rapidly parasitize pollen beetle larvae in the field (Jourdheuil 1960).

Despite the observations by Jourdheuil (1960), various authors think that adult parasitoids of the pollen beetle probably search for nectar in the field and in the surrounding environment, though no proof has yet been found (Thies et al. 2003; Jönsson et al. 2005; Zaller et al. 2009; Rusch et al. 2011). One of the potential explanations of the positive effect of landscape complexity on parasitism rates of the pollen beetle is that parasitoid populations may benefit from the higher nectar availability found in complex landscapes, suggesting nectar exploitation by parasitoids during the adult stage (Thies et al. 2003; Zaller 
et al. 2009; Rusch et al. 2011). Although there is evidence that adults of various parasitoid species generally use sugar sources to satisfy their energetic needs (Jervis et al. 1993; Steppuhn and Wäckers 2004), nothing is known about the nutritional state of pollen beetle parasitoids, despite the fact that they are major biological control agents receiving increasing attention (Ulber et al. 2010).

In the context of conservation biological control there is now a need to examine the nutritional state of pollen beetle parasitoids during foraging in the field. Moreover, collecting data about the nutritional state of biological control agents could contribute to a better understanding of patterns of predation or parasitism at the landscape level. The aim of this study is to provide detailed information on the feeding history, the nutritional state and the type of food consumed by $T$. heterocerus foraging in the field.

\section{Materials and methods}

Field sites

The experiment was conducted in 2009 and 2010 in four agricultural fields (two different fields for each year) (field area; 2009: 4.7 and 3.1 ha; 2010: 5.7 and $16.5 \mathrm{ha})$ located in the same region in north-western France in a sub-Oceanic climate zone $\left(49^{\circ} 05^{\prime} \mathrm{N}\right.$, $\left.1^{\circ} 15^{\prime} \mathrm{E}\right)$. The landscape of this region is relatively complex and mainly characterized by a mosaic of arable land and semi-natural habitats such as small forest fragments, hedgerows and grasslands. The mean proportion of semi-natural habitats in a 2,000 m radius circular sector around each field was $36.14 \pm 19.3 \%$ and was mainly composed of forest and grassland [calculated using ArcGis software (Version 9.2, ESRI)]. Oilseed rape (cv. 'Kadore') fields at least $4 \mathrm{~km}$ apart were sown by the participating farmers between the 28 August and the 3 September for both years.

\section{Insect sampling}

Tersilochus heterocerus foraging in the field were collected by sweep net sampling during flowering of oilseed rape, between 11:00 and 16:00 on two different dates for each year. Parasitoids were sampled in an area not treated with pesticides and located in the centre of each field. All individuals were sampled on the same day for each collection date. The two different dates were selected according to plant development (Fig 1) and climatic conditions (sunny, non windy and dry days). Because $T$. heterocerus appear in the crop at the beginning of flowering and are visible until the end of flowering (Ulber et al. 2010), we sampled adults in the field at these two stages. We sampled adult parasitoids at the beginning of the flowering between growth stages GS 60 and GS 62 $(\mathrm{BBCH})$. The end of flowering was defined as the period between GS 65 and GS 67. The respective sampling dates each year were: 24 April (four days after the beginning of flowering) and 5 May in 2009 (16 days after the beginning of flowering) and in 2010, 29 April (eight days after the beginning of flowering) and 17 May (26 days after the beginning of flowering) (Fig 1). Immediately after sampling, all parasitoids were stored in plastic bags at $-22{ }^{\circ} \mathrm{C}$ for subsequent identification, enumeration and analyses.

In both years, sweep net sampling was performed before the first day of flowering to ensure that no parasitoids were already foraging in the fields. Newly emerged adult specimens were obtained from cocoons (containing diapausing adults) collected in the soil of an experimental plot located at the INRA (French National Institute for Agricultural Research) experimental station, Grignon, France. Oilseed rape was grown in the plot in the previous year and was not tilled after harvest in order to maximise $T$. heterocerus survival during the following winter (Nilsson 2010). To determine the initial sugar levels at the time of emergence, $T$. heterocerus within cocoons were

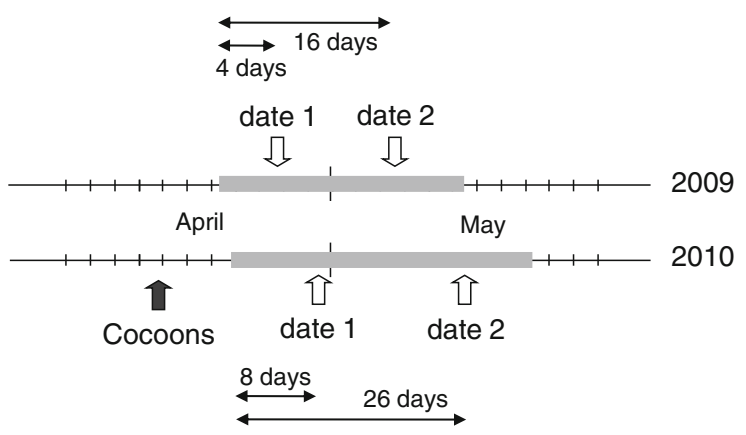

Fig. 1 Sampling dates of $T$. heterocerus at the time of emergence (cocoons, black arrow) and during (date 1 and date 2 , white arrows) flowering of oilseed rape (in grey) for 2009 and 2010. Numbers of days indicate the number of days between sampling and the beginning of flowering 
sampled 29 March 2010 just before emergence. Cocoons were extracted by washing 20 undisturbed soil cores under water. The cores were taken at equally distributed points across the field. Seventy males and 70 females $T$. heterocerous were extracted by dissecting collected cocoons and were analyzed as unfed individuals. Of these unfed $T$. heterocerus, 25 individuals of each sex were used for preliminary analysis to calibrate the minimum number of individuals required for quantifying sugar content by high-performance anion-exchange chromatography (HPAEC) analysis (data not shown).

\section{HPAEC analysis}

All parasitoids were conserved in an Eppendorf tube containing $1 \mathrm{ml} 70 \%$ ethanol and stored at room temperature until analysis. The ethanol was evaporated at room temperature and all individuals were then weighed separately with a microbalance before analysis. For each field, we analysed three replicates of pooled individuals of each sex at each date. Preliminary analysis revealed that sugar concentrations contained in one specimen were too low to quantify and using pools of five specimens was the minimum number required to allow quantification (data not shown). When possible (i.e., cocoons specimens and field-caught individuals during 2010) we used more individuals per replicate to increase the detection of the analysis. Thus, for cocoons specimens, we used three replicates of 15 individuals for each sex. For field-caught $T$. heterocerus, we used three replicates of five individuals for each field and sex in 2009 and three replicates of ten individuals for each field and sex in 2010. Pooling individuals to allow sugar quantification in parasitoids is a widely used approach in nutritional ecology studies (Casas et al. 2003; Lee et al. 2006; Winkler et al. 2010). To compare the measured concentrations between treatments, sugar amounts were expressed relative to the parasitoid weight. Parasitoids were placed in $500 \mu \mathrm{l}$ of ultrahighquality water $(18.2 \mathrm{~m} \Omega)$ and crushed using an automatic homogenizer $\left(\mathrm{IKA}^{\circledR}{ }^{\circledR}\right.$ RW14 basic). Specimens were then centrifuged at 13,000 r.p.m. for $10 \mathrm{~min}$. We collected $500 \mu \mathrm{l}$ of the supernatant and passed it through a $0.2 \mu \mathrm{m}$ mixed cellulose ester membrane filter using a $1 \mathrm{ml}$ syringe $\left(\right.$ Hamilton $\left.^{\circledR}\right)$. For each sample, $120 \mu \mathrm{l}$ was injected into HPAEC Dionex ICS3000 equipment. Separation of carbohydrates was carried out on a CarboPac PA-1 guard column $(4 \times 50 \mathrm{~mm})$ and a CarboPac PA-1 anion-exchange column $(4 \times 250 \mathrm{~mm})$ using $\mathrm{H}_{2} \mathrm{O}$ (eluent $\left.\mathrm{A}\right)$ and $250 \mathrm{mM} \mathrm{NaOH}$ with $4 \mathrm{mM}$ sodium acetate (eluent $\mathrm{B}$ ) under isocratic mode with the A/B ratio $(48: 52$, v/v) as mobile phase at a constant flow rate of $0.7 \mathrm{ml} \mathrm{min}^{-1}$. Carbohydrates were monitored by pulsed amperometric detection. Curves of sugars were obtained for sorbitol, mannitol, trehalose, glucose, fructose, melibiose, saccharose, melezitose, raffinose and erlose by injecting calibration standards with different concentrations of 2.5, 5, 7.5, 10, 12.5 and 15 nmoles of these sugars. The concentrations of each sugar were analyzed using the program CHROMELEON version 6.7. The limits of detection (LOD) ranged from $2.6 \mu \mathrm{g}$ $\mathrm{ml}^{-1}$ for sorbitol to $7.4 \mu \mathrm{g} \mathrm{ml}{ }^{-1}$ for erlose. The limit of quantification (LOQ) was calculated according to the limit of detection, following: $\mathrm{LOQ}=3 \times \mathrm{LOD}$.

Physiological parameters

We used two different physiological parameters to describe the nutritional state and the feeding history of field collected parasitoids (Steppuhn and Wäckers 2004; Desouhant et al. 2010). We used the overall sugar content resulting from the sum of all amounts of all sugar types and the ratio between the sum of all amounts of all sugar types except fructose and the sugars sum (defined as the $\rho$ ratio by Desouhant et al. (2010)). Laboratory approaches on several parasitoid species have demonstrated that the overall sugar content provides information on the time since the last meal (parasitoids that fed recently having a higher total amount of sugar than earlier-fed or starved individuals) and that the $\rho$ ratio enables the differentiation between fed and unfed parasitoids (unfed individuals having a higher index than fed ones) (Steppuhn and Wäckers 2004; Desouhant et al. 2010). In the present study we only measured carbohydrate amounts as they are a good indicator of the acquisition of food in non host-feeding parasitoids (Desouhant et al. 2010), like T. heterocerus. Because larger individuals were assumed to have greater nutrient stores, the measured sugar concentrations were expressed relative to insect weight. 
Statistical analysis

The data were not normally distributed and the variance heterogeneity was high. Therefore, we compared sugar content and $\rho$ ratio between dates for each year and sex using the non-parametric Kruskal-Wallis ANOVA $(\alpha=0.05)$. Post-hoc comparisons of mean ranks between dates were made following Siegel and Castellan (1988). Differences in sugar content and $\rho$ ratio between sexes from the same date were analysed using the Mann-Whitney $U$ test. All statistical analyses were performed using the statistical program $\mathrm{R}$ (version 2.8, 2008).

\section{Results}

Sugar levels at the time of emergence

The total amount of sugars in $T$. heterocerus parasitoids at the time of emergence was $0.74 \pm 0.25 \mu \mathrm{g}$ (mean $\pm \mathrm{SE} ; n=6$ ) per $\mathrm{mg}$ of parasitoid. We found no statistical difference between the total amount of sugars contained in males and females in cocoons specimens (Mann-Whitney $U$ test, $\mathrm{W}=1 ; P=0.2$ ). Males contained an average of $0.39 \pm 0.26 \mu \mathrm{g}$ total sugars per $\mathrm{mg}$ of parasitoid $(n=3)$ and females contained an average of $1.08 \pm 0.36 \mu \mathrm{g} \mathrm{mg}^{-1}$ of parasitoid $(n=3)$. However, in terms of composition, the HPAEC sugar spectrums revealed differences between males and females at the time of emergence. Trehalose was the main sugar found in females. HPAEC sugar spectrums revealed that males contained trehalose, glucose and fructose.

\section{Sugar levels of males and females in the field}

The total amounts of sugar in parasitoids sampled in the field are presented in Fig. 2. We found a significant effect of sampling date on sugar content of both males $\left(\chi^{2}=7.56, \mathrm{df}=2, P=0.02\right)$ and females $\left(\chi^{2}=\right.$ 10.73 , df $=2, P<0.01)$ in 2009. At the beginning of flowering (i.e. 24 April; date 1), the total amount of sugars for both sexes was significantly lower than their respective values in cocoons specimens (Fig. 2) because no sugars were found at quantifiable levels, although trehalose and saccharose were detected during the analysis. At the end of flowering in 2009, the sugar content of males rose to $0.97 \pm 0.49$
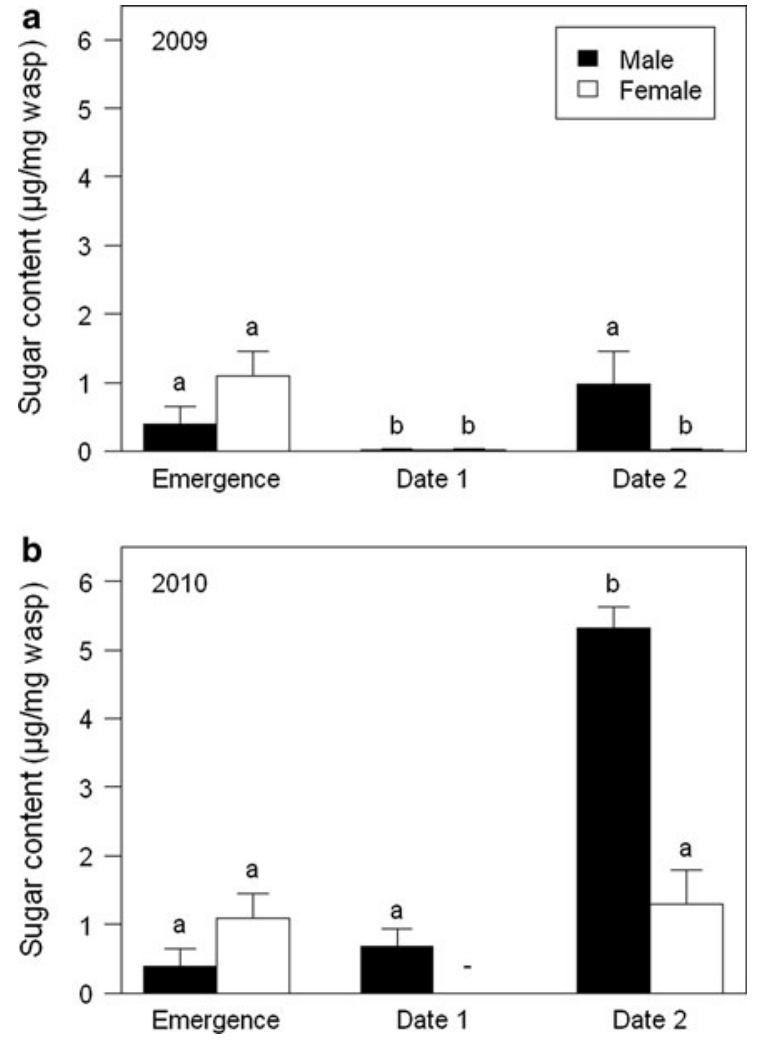

Fig. 2 Mean total sugar amounts (+ SE) measured in adult $T$. heterocerus at the time of emergence and when foraging in the fields in 2009 (a) and 2010 (b). Sugar content values at the time of emergence are from the same specimens and are reported in both graphs to make comparisons easier. Hyphen in the female column indicates that no specimens were sampled at this date. Different letters indicate significant differences between dates for each sex $(\alpha=0.05)$

$\mu \mathrm{g} \mathrm{m}^{-1}$ of parasitoid (mainly glucose and fructose) but no sugars were quantifiable for females (Fig. 2). At the end of flowering, the total amount of sugars for males was significantly higher than the sugar content of males at the beginning of flowering but there was no significant difference when compared to the sugar content of males at the time of emergence (Fig. 2).

In 2010, we found a significant effect of sampling date on sugar content of males $\left(\chi^{2}=10.42, \mathrm{df}=2\right.$, $P<0.01)$ and no effect on sugar content of females. Only males were captured at the beginning of flowering and the total amount of sugars at that time was not significantly different from the amount of sugars in the male specimens at the time of emergence (Fig. 2). Sugars in males at emergence were mainly composed of glucose and fructose although trehalose, melibiose 
and saccharose were also detected in insufficient amounts for quantification. At the end of flowering during 2010, the total amount of sugars in males was significantly higher than sugar content of males at the time of emergence and at the beginning of flowering when it rose to $5.32 \pm 0.31 \mu \mathrm{g}$ per $\mathrm{mg}$ of parasitoid (Fig. 2). Females sampled at the end of flowering in 2010 were found to contain $1.29 \pm 0.50 \mu \mathrm{g}$ of total sugar per mg of parasitoid (Fig. 2). This was significantly lower than the sugar content of males on the same date but not significantly different from the female specimens at the time of emergence or from the sugar content of males at the beginning of flowering. Sugars from males and females at this date were mainly composed of glucose and fructose although melibiose, saccharose and erlose were also detected in insufficient amounts for quantification.

When considering the two years together and normalising sampling dates according to the number of days after the beginning of flowering to account for variability in sampling dates between years, we found that the total amount of sugars in parasitoids increased with the number of days after the beginning of flowering. No sugars were found in parasitoids caught four days after the beginning of flowering (date 1 in 2009), while the total amounts of sugars in males sampled eight days (date 1 in 2010) and 16 days (date 2 in 2009) after the beginning of flowering were $0.68 \pm 0.26$ and $0.97 \pm 0.49 \mu \mathrm{g} \mathrm{mg}^{-1}$ of parasitoid respectively. At eight and 16 days after the beginning

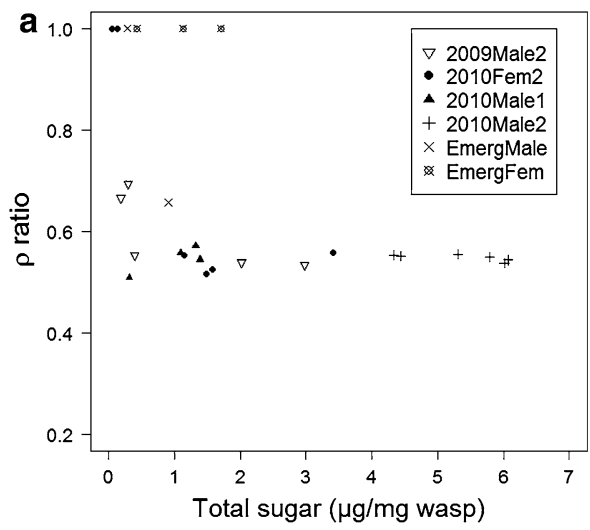

Fig. 3 Plot of the overall sugar content $\left(\mu \mathrm{g} \mathrm{mg} \mathrm{g}^{-1}\right.$ of wasp) versus the $\rho$ ratio for each pool of individuals sampled at the time of emergence and sampled in the field and for each treatment: sex (male/female), sampling date (date 1/date 2), year of flowering, the total amounts of sugars in males were not significantly different from those in unfed individuals. After 26 days from flowering (date 2 in 2010), we found significantly higher amounts of sugars than at any other date after the beginning of flowering for

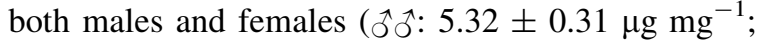
우우: $\left.1.29 \pm 0.50 \mu \mathrm{g} \mathrm{mg}^{-1}\right)$.

The $\rho$ ratio values and patterns of feeding history in the field

The $\rho$ ratio for specimens at the time of emergence was $0.55 \pm 0.29$ for males and $1.00 \pm 0.00$ for females (Fig. 3). In 2009, the $\rho$ ratios at the beginning of flowering for males and females and at the end of flowering for females were zero as no sugars were quantifiable. There was a significant effect of sampling date on the $\rho$ ratio values for males $\left(\chi^{2}=7.2132\right.$, $\mathrm{df}=2, P=0.02)$. At the end of the flowering period the $\rho$ ratio value was $0.50 \pm 0.10$ for males (Fig. 3). This value was significantly different from the $\rho$ ratio at the beginning of flowering but not significantly different from the ratio of males at the time of emergence.

In 2010, we found no significant differences between the $\rho$ ratios of males at the time of emergence, the beginning of flowering and the end of flowering $\left(\chi^{2}=1.36, \mathrm{df}=2, P=0.50\right)$ (Fig. 3). The $\rho$ ratio of females at the end of flowering in 2010 was not significantly different than the $\rho$ ratio of females at the time of emergence $\left(\chi^{2}=2.88, \mathrm{df}=1, P=0.09\right)$.

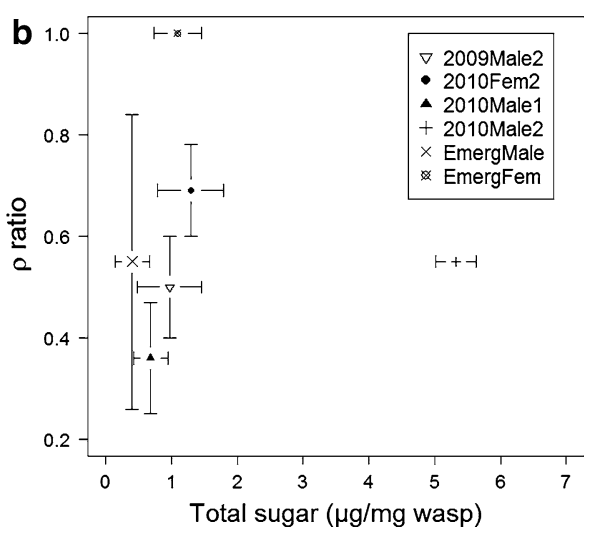

(2009/2010). Plot a represents the values of each replicate and plot b summarizes data by the mean $\pm \mathrm{SE}$ in the two dimensions of the graph 
The combination of the total amount of sugar and the $\rho$ ratio values made it possible to discriminate between females that had fed before being caught in the field and females at the time of emergence (i.e. unfed) (Fig. 3). These two physiological parameters also made it possible to distinguish between $T$. heterocerus caught in the field at the beginning and at the end of flowering (Fig. 3).

\section{Discussion}

Floral resources in agroecosystems can stimulate natural enemy populations and the regulatory function they provide (Gurr et al. 2005; Heimpel and Jervis 2005). Indeed, it can increase natural enemies' efficiency by increasing longevity and fecundity, or changing the sex ratio (Berndt and Wratten 2005). However, knowledge about energy acquisition in the field of pollen beetle parasitoids had never been examined before.

The major finding of this study is that one of the most abundant and widespread univoltine parasitoids of the pollen beetle, T. heterocerus, feeds on sugar when foraging in the field. The overall content of sugar found in cocoons and foraging individuals suggests that (i) T. heterocerus emerge with relatively small amounts of sugar composed mainly of trehalose, glucose and fructose; (ii) the first parasitoids caught just after they appeared in the field had already consumed high amounts of sugar reserves; and (iii) the total amount of sugars then increases with the number of days since the beginning of oilseed rape flowering.

The presence of the disaccharide trehalose [the common insect haemolymph sugar, (Wäckers 2001)] in $T$. heterocerus at the time of emergence can be interpreted as the result of parasitoid larvae feeding on its host (i.e. the pollen beetle larva) just after pollen beetle pupation in the soil. Indeed, if it is assumed that T. heterocerus is a non host-feeding parasitoid at the adult stage, young parasitoid larvae developing in pollen beetle larvae have no lipid reserves in early development stages and, thus, feed on host haemolymph for maintenance and development (Jourdheuil 1960). In field-caught parasitoids the sugar spectrums never revealed trehalose. Steppuhn and Wäckers (2004) explained that absence of trehalose in adult parasitoids is surprising as it is reported in the literature that insects metabolize glucose into trehalose. Trehalose is assumed to be involved in different functions such as energy storage, cryoprotection, thermal and osmotic stress, and feeding behaviour and nutrient intake (Thompson 2003). This difference in trehalose between justemerged and field-caught individuals together with recent results on the nutritional state of other parasitoid species raises important questions about the role of trehalose and the success of functions usually assigned to trehalose (Steppuhn and Wäckers 2004; Vattala 2005). Further experiments on the role of trehalose involving different parasitoid species are therefore needed.

Flight is a highly energy-demanding behaviour and carbohydrates are known to constitute the main fuel for flight in most hymenopteran species (Casas et al. 2003; Wanner et al. 2006). Moreover, T. heterocerus emerges from previous year oilseed rape fields and is assumed to fly towards the host field by upwind anemotaxis, directly searching for hosts (Jourdheuil 1960; Williams et al. 2007). Hence, such flying patterns represent substantial energy consumption for parasitoids, which could explain why $T$. heterocerus individuals sampled at the beginning of flowering (i.e. just after arriving in the fields) have lower levels of sugar content than individuals at the time of emergence in 2009. Due to climatic conditions, the earliest sampling in 2010 occurred later than in 2009. Parasitoids may have been able to feed on sugar sources eight days after the beginning of flowering in 2010. This may explain why we found no difference in sugar content between specimens at emergence and at the beginning of flowering for 2010.

The combination of the total amount of sugar and the $\rho$ ratio made it possible to discriminate between females that had fed before being caught in the field and females at the time of emergence (i.e. unfed), as the latter had significantly higher $\rho$ ratios and significantly lower amounts of sugar than field-caught $T$. heterocerus females. However, the $\rho$ ratios of males at the time of emergence showed high variability and it was not possible to differentiate between males caught in the field and males caught at the time of emergence. This is undoubtedly due to the fact that we found no sugars in one of the three pooled replicates for males at the time of emergence whereas the other two had relatively high ratios equivalent to the values of unfed females ( $\rho$ ratios $=1.00$ and 0.65 , Fig 3 ). As the HPAEC is able to detect very low amounts of sugars in the standards $\left(0.56 \mu \mathrm{g} \mathrm{ml}^{-1}\right)$, we have strong confidence in the results displayed by our analyses. 
All field-caught specimens that had fed (i.e. where we were able to quantify sugar amounts) had comparable $\rho$ ratios $(\approx 0.5)$, which were significantly lower than those of females in cocoons, and an overall content of sugar increasing with the number of days after the beginning of flowering. This indicates that $T$. heterocerus foraging in the field consume sugar and that adults caught at the end of flowering have consumed more sugar or have fed more recently than individuals at the beginning of flowering. These new results for this species are consistent with previous findings for other parasitoid species in which sugar consumption in the field have been found (Casas et al. 2003; Lavandero et al. 2005; Lee et al. 2006). Because the koinobiont parasitoid $T$. heterocerus does not feed on hosts during the imaginal stage and has never been observed feeding on honeydew (Jourdheuil 1960), our results strongly suggest that adults use nectar for carbohydrate acquisition after host field localization when foraging in the field and its surroundings.

Our results showed that at the end of flowering the sugar content of females was zero in 2009 and comparable to the sugar content of males at the beginning of flowering in 2010. These results are consistent with the knowledge about $T$. heterocerus biology and ecology. Jourdheuil (1960) reported that males always emerge a few weeks before females (protandry phenomenon, confirmed by our data in 2010) and that the sexes have very different behaviours. After emergence females immediately and actively forage for hosts in the field whereas males tend to fly in groups and can be found in the field and its immediate surroundings. Therefore, the higher amount of sugar found in males may be due to the fact that they have much more time for food-foraging in the crop and in adjacent habitats or that they consume less energy than the females actively seeking hosts.

Tersilochus heterocerus may use oilseed rape nectar as it represents an enormous amount of food in the landscape during flowering (Westphal et al. 2003). Nectars of numerous oilseed rape cultivars have been examined and provide unambiguous evidence that oilseed rape nectar is predominantly composed of glucose and fructose and that the total amounts of sugar are higher at the beginning of flowering than at the end (Pierre et al. 1999). However, T. heterocerus is present in oilseed rape fields until the end of flowering (Ulber et al. 2010; personal observation). Therefore, providing key floral resources within the field or in its immediate vicinity towards the end of flowering might be a promising way to strengthen the top-down impact of parasitoid on the herbivore population.

This study provides the first evidence of the acquisition of carbohydrates in the field by $T$. heterocerus, one of the major parasitoid species of the pollen beetle. Several studies on various nectarfeeding species have demonstrated that providing floral resources increases longevity and fecundity of parasitoids and may enhance biological control of herbivores (Lee et al. 2006; Lee and Heimpel 2008; Bianchi and Wäckers 2008; Luo et al. 2010). We have provided evidence that $T$. heterocerus uses nectar when foraging in the field. Further research should explore the effect of various flowering plants (including oilseed rape) and sugars on longevity and fecundity of $T$. heterocerus and the subsequent parasitism rates of pollen beetle larvae. In a long-term perspective it can orientate breeders in selecting oilseed rape cultivars producing adapted amounts of sugars at key periods for parasitoids, such as the beginning of flowering, to strengthen biological control (Pierre et al. 1999; Tompkins et al. 2010). However, other aspects such as the effect of agronomic practices, characteristics linked to plant attractiveness, nectar accessibility, as well as trade-offs and synergies with other plant parameters should be clarified before including it in plant selection programs. Finally, studying the nutritional state of parasitoids in the field in different landscape contexts to examine the impact of floral and nectar resources in extra-field habitats should yield very interesting perspectives and major challenges for conservation biological control.

Acknowledgments We would like to thank the participating farmers, and A. Butier and G. Grandeau for their technical assistance. We thank Anne-Marie Cortesero and Barbara Ekbom for helpful comments on an earlier version of the manuscript. We also thank Christer Nilsson for his precious help and Donald White for helpful editorial advice in English.

\section{References}

Berndt LA, Wratten SD (2005) Effects of alyssum flowers on the longevity, fecundity, and sex ratio of the leafroller parasitoid Dolichogenidea tasmanica. Biol Control 32:65-69

Berndt LA, Wratten SD, Hassan PG (2002) Effects of buckwheat flowers on leafroller (Lepidoptera: Tortricidae) parasitoids in a New Zealand vineyard. Agric For Entomol $4: 39-45$ 
Bianchi FJJA, Wäckers FL (2008) Effects of flower attractiveness and nectar availability in field margins on biological control by parasitoids. Biol Control 46:400-408

Bianchi FJJA, Booij CJH, Tscharntke T (2006) Sustainable pest regulation in agricultural landscapes: a review on landscape composition, biodiversity and natural pest control. Proc R Soc 273:1715-1727

Casas J, Driessen G, Mandon N, Wielaard S, Desouhant E, van Alphen J, Lapchin L, Rivero A, Christides JP, Bernstein C (2003) Energy dynamics in a parasitoid foraging in the wild. J Anim Ecol 72:691-697

Costamagna AC, Menalled FD, Landis DA (2004) Host density influences parasitism of the armyworm Pseudaletia unipuncta in agricultural landscapes. Basic Appl Ecol 5:347-355

Desouhant E, Lucchetta P, Giron D, Bernstein C (2010) Feeding activity pattern in a parasitic wasp when foraging in the field. Ecol Res 25:419-428

Gurr GM, Wratten SD, Tylianakis J, Kean J, Keller M (2005) Providing plant foods for natural enemies in farming systems: Balancing practicalities and theory. In: Wäckers FL, van Rijn P, Bruin J (eds) Plant-provided food for carnivorous insects: a protective mutualism and its applications. Cambridge University Press, Cambridge, UK, pp. 326-347

Hawkins BA, Cornell HV, Hochberg ME (1997) Predators, parasitoids, and pathogens as mortality agents in phytophagous insect populations. Ecology 78:2145-2152

Heimpel GE, Jervis MA (2005) Does floral nectar improve biological control by parasitoids? In: Wäckers FL, van Rijn $\mathrm{P}$, Bruin $\mathrm{J}$ (eds) Plant-provided food for carnivorous insects: a protective mutualism and its applications. Cambridge University Press, Cambridge, UK, pp. 326-347

Jervis MA, Kidd NAC, Fitton MG, Huddleston T, Dawah HA (1993) Flower-visiting by hymenopteran parasitoids. J Nat History 27:67-105

Jönsson M, Lindkvist A, Anderson P (2005) Behavioural responses in three ichneumonid pollen beetle parasitoids to volatiles emitted from different phenological stages of oilseed rape. Entomol Exp Appl 115:363-369

Jourdheuil P (1960) Influence de quelques facteurs écologiques sur les fluctuations de population d'une biocénose parasitaire. Etude relative à quelques Hyménoptères parasites de divers Coléoptères inféodés aux Crucifères. Annales Des Epiphyties (11): 445-660

Landis DA, Wratten SD, Gurr GM (2000) Habitat management to conserve natural enemies of arthropod pests in agriculture. Ann Rev Entomol 45:175-201

Lavandero B, Wratten S, Shishehbor P, Worner S (2005) Enhancing the effectiveness of the parasitoid Diadegma semiclausum (Helen): movement after use of nectar in the field. Biol Control 34:152-158

Lee JC, Heimpel GE (2008) Floral resources impact longevity and oviposition rate of a parasitoid in the field. J Anim Ecol 77:565-572

Lee JC, Andow DA, Heimpel GE (2006) Influence of floral resources on sugar feeding and nutrient dynamics of a parasitoid in the field. Ecol Entomol 31:470-480

Luo SP, Li JC, Liu XX, Lu ZY, Pan WL, Zhang QW, Zhao ZW (2010) Effects of six sugars on the longevity, fecundity and nutrient reserves of Microplitis mediator. Biol Control 52: $51-57$
Nilsson C (2010) Impact of soil tillage on parasitoids of oilseed rape pests. In: Williams IH (ed), Biocontrol-based integrated management of oilseed rape pests. Springer, London, UK, pp 45-76

Pierre J, Mesquida J, Marilleau R, Pham-Delegue MH, Renard M (1999) Nectar secretion in winter oilseed rape, Brassica napus-quantitative and qualitative variability among 71 genotypes. Plant Breed 118:471-476

Rusch A, Valantin-Morison M, Sarthou JP, Roger-Estrade J (2011) Multi-scale effects of landscape complexity and crop management on pollen beetle parasitism rate. Landsc Ecol 26(2011):473-486

Siegel S, Castellan NJ (1988) Non parametric statistics for the behavioral sciences. McGraw-Hill, New York, USA

Steppuhn A, Wäckers FL (2004) HPLC sugar analysis reveals the nutritional state and the feeding history of parasitoids. Funct Ecol 18:812-819

Thies C, Steffan-Dewenter I, Tscharntke T (2003) Effects of landscape context on herbivory and parasitism at different spatial scales. Oikos 101:18-25

Thompson SN (2003) Trehalose-the insect blood sugar. Adv Insect Physiol 31:205-285

Tompkins JML, Wratten SD, Wäckers FL (2010) Nectar to improve parasitoid fitness in biological control: does the sucrose:hexose ratio matter? Basic Appl Ecol 11:264-271

Tylianakis JM, Didham RK, Wratten SD (2004) Improved fitness of aphid parasitoids receiving resource subsidies. Ecology 85:658-666

Ulber B, Williams IH, Klukowski Z, Luik A, Nilsson C (2010) Parasitoids of oilseed rape pests in Europe: key species for conservation biocontrol. In: Williams IH (ed) Biocontrolbased integrated management of oilseed rape pests. Springer, London, UK, pp 45-76

Vattala HD (2005) Enhancement of the efficacy of the parasitoid Microtonus hyperodae Loan (Hymenoptera: Braconidae) by provision of floral resources to improve biological control of its host, the Argentine stem weevil (Listronotus bonariensis) (Kuschel) (Coleoptera: Curculionidae). Ph.D. thesis, Lincoln University, New Zealand

Wäckers FL (2001) A comparison of nectar- and honeydew sugars with respect to their utilization by the hymenopteran parasitoid Cotesia glomerata. J Insect Physiol 47:10771084

Wäckers FL, van Rijn P (2005) Food for protection: an introduction. In: Wackers FL, van Rijn P, Bruin J (eds) Plantprovided food for carnivorous insects: a protective mutualism and its applications. Cambridge University Press, Cambridge, UK, pp 1-14

Wanner H, Gu H, Dorn S (2006) Nutritional value of floral nectar sources for flight in the parasitoid wasp, Cotesia glomerata. Physiol Entomol 31:127-133

Westphal C, Steffan-Dewenter I, Tscharntke T (2003) Mass flowering crops enhance pollinator densities at a landscape scale. Ecol Lett 6:961-965

Williams IH, Frearson D, Barari H, McCartney A (2007) First field evidence that parasitoids use upwind anemotaxis for host-habitat location. Entomol Exp Appl 123:299-307

Winkler K, Wäckers F, Bukovinszkine-Kiss G, van Lenteren J (2006) Sugar resources are vital for Diadegma semiclausum fecundity under field conditions. Basic Appl Ecol $7: 133-140$ 
Winkler K, Wäckers F, Termorshuizen A, van Lenteren J (2010) Assessing risks and benefits of floral supplements in conservation biological control. BioControl 55:719-727

Zaller JG, Moser D, Drapela T, Schmoger C, Frank T (2009) Parasitism of stem weevils and pollen beetles in winter oilseed rape is differentially affected by crop management and landscape characteristics. BioControl 54:505-514

\section{Author Biographies}

Adrien Rusch is a researcher at INRA in the SAVE research unit. His current research is mainly focused on the ecological processes underlying natural control of pest populations in agroecosystems. Among other issues, he focuses on the relative influence of farming practices and landscape characteristics on pest and natural enemy communities as well as their trophic interactions. The aim of his research is to produce knowledge to support the design of innovative crop protection and land use strategies by maximizing delivery and use of ecosystem services.

Séverine Suchail is an associate professor at the University of Avignon, France, where she teaches metabolic biochemistry, enzymology and ecotoxicology. She is associated to the Biomarkers and Environmental Bioindicators Department at the Mediterranean Institute of marine and terrestrial Biodiversity and Ecology. Her research interest is mainly focused on the impacts of pesticides and agricultural practices on terrestrial invertebrates.
Muriel Valantin-Morison is a researcher at INRA in the Agronomie research unit. She works on the development of methods for the design of pesticide-free crop management in winter oilseed rape. Since 2007, she has been working on the effects of cropping practices in the field and in the surrounding landscape as well as the proportion of semi-natural habitats on pest dynamics in winter oilseed rape.

Jean-Pierre Sarthou is an associate Professor at INP-ENSAT, France, where he teaches entomology in crop protection, conservation biological control and agroecology to undergraduate and graduate students. His research interests cover both bioindication and conservation ecology through the issue of ecological services maximisation in agroecosystems. He is associated to the INRA AGIR research unit.

Jean Roger-Estrade is head Professor at AgroParistech, where he teaches agronomy and agroecology to undergraduate and graduate students, with, for the later, a special interest for the design of crop management systems based on agroecolgical principles. His research interests are conservation agriculture, soil tillage, soil ecology, with a special attention to the effects of tillage on weeds and pest dynamics. He is associated to the INRA agronomy research unit, based at Grignon, Northern France. 